Original Research

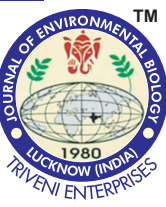

DOI : http://doi.org/10.22438/jeb/40/3(SI)/Sp-15

\title{
Analysis of biodrugs extracted from kiwi fruit by FT- IR and GC-MS
}

\section{Authors Info \\ S. Dong', H. Bi', D. Zheng ${ }^{2}$, Y. Li', Y. Zhao ${ }^{2 *}$ and W. Peng ${ }^{2 *}$ \\ ${ }^{1}$ Scientific Research Institution, Henan Xiaoqinling National Nature Reserve Administration Bureau, SanMenXia, 472 500, China \\ ${ }^{2}$ School of Forestry, Henan Agricultural University, \\ Zhengzhou, 450 002, Henan, China \\ *Corresponding Author Email : pengwanxi@163.com}

\section{Edited by}

Prof. Ahmed Jalal Khan Chowdhury

\section{Reviewed by}

Dr. Hui Ouyang

Dr. Dangquan Zhang

\section{Abstract}

Aim: This study aim to analyse Biodrugs extracted from kiwi fruit by FT-IR and GC-MS. Kiwi fruit is rich in nutrients and trace elements.

Methodology: In this study, Fourier Transform Infrared Spectroscopy (FT-IR) and Gas ChromatographyMass Spectrometry (GC-MS) technologies were carried out to detect and analyze the chemical composition of kiwi fruit.

Results: FT-IR detection revealed that the main chemical components of kiwi fruit were cellulose, phenol, alcohol, alkane and alkenen. GC-MS detection, showed high contents of 5-hydroxymethylfurfural; alpha--rhamnopyranose; 2,3-dihydro-3,5-dihydroxy-6-methyl-4(H)-pyran-4-one; D-alanine, Npropargyloxycarbonyl-, isohexyl ester; resorcinol; dodecanoic acid, 3-hydroxy-; melezitose and furfural.

Interpretation: These compositions can be used within thefood, cosmetic and chemical engineering fields.

Key Words: Bioactive constituents, Biodrugs, Kiwi fruit

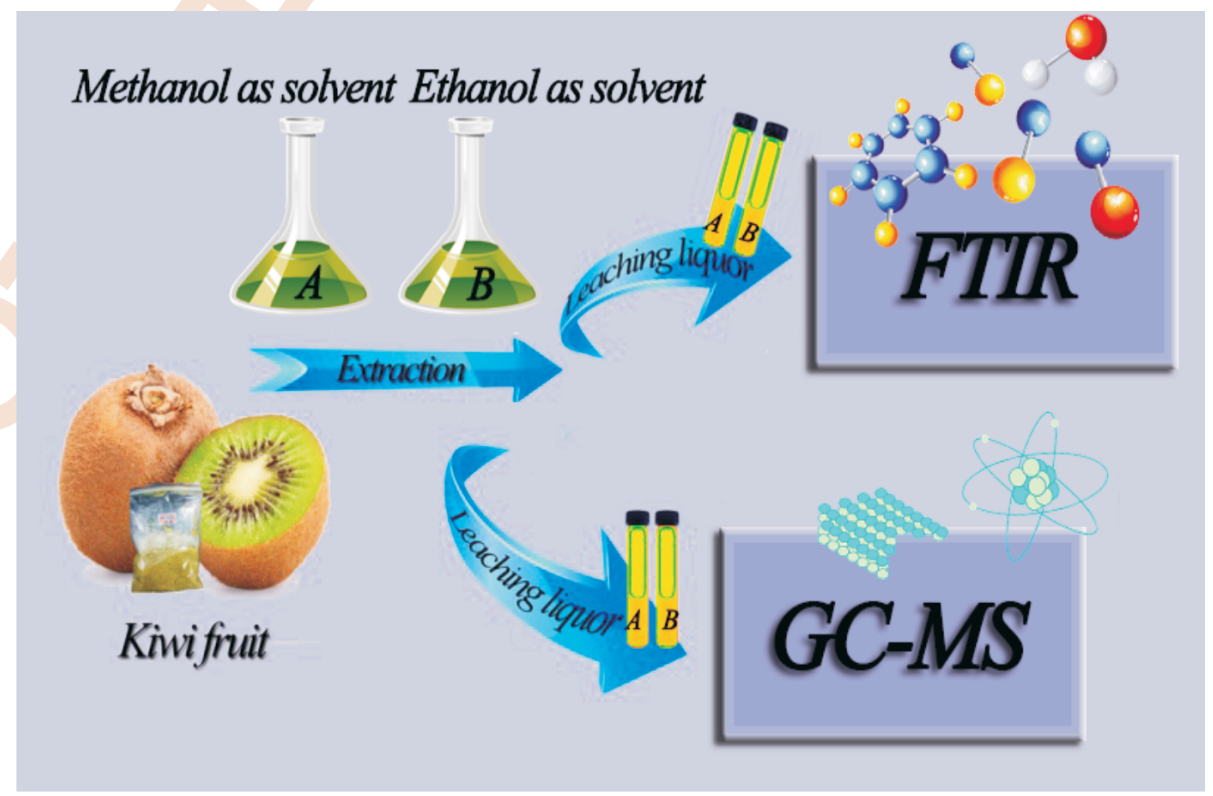

Citation: Dong, S., H. Bi, D. Zheng, Y. Li, Y. Zhao and W. Peng: Analysis of biodrugs extracted from kiwi fruit by FT-IR and GC-MS. J. Environ. Biol., 40, 509-514 (2019). 


\section{Introduction}

Kiwi fruit (Actinidia chinensis Planch) belongs to family Actinidiaceae. It is rich in nutrients, essential trace elements and various amino acids, such as calcium, potassium, selenium, zinc, tellurium, vitamin $\mathrm{C}$, fructose, citric acid, malic acid, fat, antioxidants, flavonoids, carotenoids, anthocyanins, folate/melatonin. Kiwi fruit also has outstanding medicinal value. It has heat-clearing and detoxifying elements, improves appetite, promotes digestion and has anticancer properties. It may also have some sleep improvement effects (Liu and Chen, 2001; Nodtvedt et al., 2017; Halin et al., 2017).

The main chemical components of kiwi fruit reported earlier by GC-MS analysis are hexadecenoic acid; octanoic acid; oleic acid butanoic acid; 3-hydroxy-, ethyl ester; (Z, Z)-9, 12-octadecadienoic acid; 1, 2, 4-trihydroxy-p-menthane; and (E)-2-Hexenal. Ethyl butanoate, E-2- hexenal, and hexenal gives the characteristic fragrance to kiwi fruit (Hua et al., 2002; Abd Samad et al., 2017).

Kiwi fruit was originally a wild fruit native to Yichang City Hubei Province, China. A New Zealander brought back Kiwi fruit from Yichang City, from wild to artificial cultivation. Till now, many varieties of kiwi fruit have been developed. They have become increasingly popular due to its nutritional value and excellent economic benefits (Atikuzzaman et al., 2018; Howlader et al., 2018). However, the main producing countries of Kiwi fruit are Italy, New Zealand and Chile (De'nan et al., 2017). Chinese-made varieties are rarely exported, and market conditions are not as good as foreign varieties. Is the nutritional value of kiwi fruit produced in China worse than its foreign counterparts? In order to understand this problem to a certain extent, in this study FTIR and GC-MS technologies were used to analyze the components of Kiwi fruit produced in the forest area of Xixia County, Henan Province, China (Yong et al., 2017; Alfarooq et al., 2017). After being artificially cultivated, the different places of origin for kiwi fruit may differ in composition. The kiwi fruit used in this study was produced in the forest area of Xixia County, Henan Province, China. Other scholars of our research group also discussed kiwi fruit produced in other locations. It is hoped that this research project will work with other scholars' projects to enrich and expand upon the available data related to the research of kiwi fruit composition (Sharma and Yadav, 2017). Therefore, kiwi fruit was extracted and analysed by FT-IR and GC-MS for the potential nutrients and trace elements.

\section{Methods and Materials}

Experimental methods: Kiwi fruits were washed with deionized water and crushed with pericarp to conduct an extraction experiment by methanol and ethanol. The leaching liquor was then put into a rotatory evaporator to evaporate the water and redundant solvents.

The kiwi fruit used in this study was collected from the forest of Xixia County (Nanyang City), Henan Province, China.
Located between $110^{\circ} 58^{\prime}-113^{\circ} 49^{\prime}$ E longitude, $32^{\circ} 17^{\prime}-33^{\circ} 48^{\prime} \mathrm{N}$ latitude at an altitude of $105-133 \mathrm{~m}$. The fruit was located in the transition zone from the north subtropical to the temperate zone, belonging to a typical monsoon continental wet climate. Adequate sunshine, plenty rainfall, and four distinct seasons characterize the environmental factors of the study area (Herrera-Franco et al., 2017). The annual average temperature of the study area $15^{\circ} \mathrm{C}$, the average frost-free period is 230 days, and annual rainfall is 700 1200 mm.

FTIR analysis: To detect liquid sample components of requires a spacer slice that limits the optical path length and sample volume. $\mathrm{KBr}$ was used as salt slice to clamp the spacer slice. The spectrum range was set at $400-4000 \mathrm{~cm}^{-1}$.

GC-MS analysis: Chromatographic column was HP-5MS (30 m $\times 250 \mu \mathrm{m} \times 0.25 \mu \mathrm{m}$ ) with an elastic quartz capillary column. High purity helium was used as carrier gas, with the flow velocity of $1 \mathrm{ml}$ $\mathrm{min}^{-1}$, and split ratio of 20: 1 . The temperature of GC program began at $50^{\circ} \mathrm{C}$, raised to $250^{\circ} \mathrm{C}$ at a velocity of $8^{\circ} \mathrm{C} \mathrm{min}{ }^{-1}$, and then raised to $300^{\circ} \mathrm{C}$ at a velocity of $5^{\circ} \mathrm{C} \mathrm{min}^{-1}$. The range of MS program scanning quality was $300-600 \mathrm{amu}$. The ionization current was $150 \mu \mathrm{A}$, and ionization voltage was $70 \mathrm{eV}$. lon source and quadrupole temperature were $230^{\circ} \mathrm{C}$ and $150^{\circ} \mathrm{C}$, respectively.

\section{Results and Discussion}

From Table 1 it can be observed that the two curves of leaching liquor, which were extracted by methanol and ethanol showed a similar trend. However, the same absorption peak attribution of two kinds of sample had different wave numbers. Attributable to the interaction between sample molecules and solvent molecules, the vibration frequency and vibration intensity of sample molecules changed. At $3575-3205 \mathrm{~cm}^{-1}$, they both had a strong and wide $\mathrm{O}-\mathrm{H}$ stretching vibration absorption peak and at 1460-1400 $\mathrm{cm}^{-1}$, the absorption peak was $\mathrm{CH}_{2}, \mathrm{CH}_{3}$ flexural vibration. These groups may be derived from alkanes in the

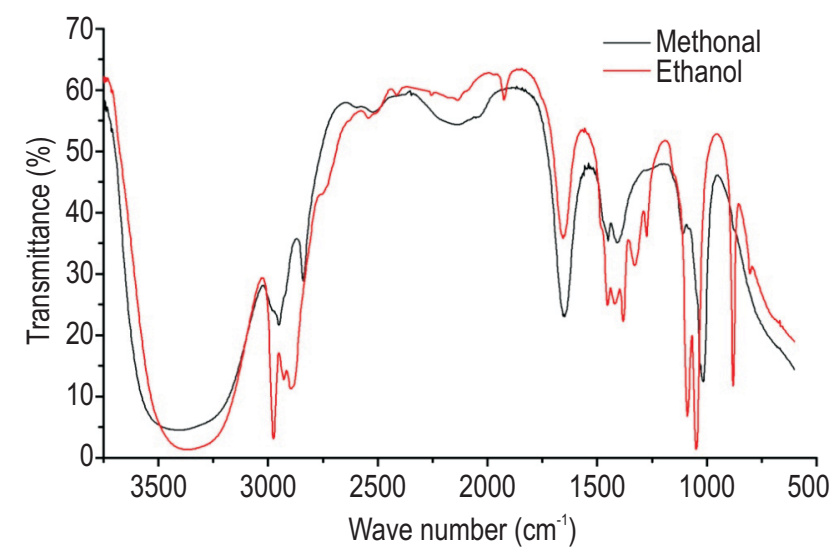

Fig. 1 : FTIR spectrogram of kiwi fruit leaching liquor. 
Table 1: FTIR detection result and analysis of kiwi fruit leaching liquor

\begin{tabular}{|c|c|c|c|c|}
\hline \multirow[t]{2}{*}{ Spectral range $\left(\mathrm{cm}^{-1}\right)$} & \multicolumn{2}{|c|}{ Absorption peak $\left(\mathrm{cm}^{-1}\right)$} & \multirow[t]{2}{*}{ Absorption peak attribution } & \multirow[t]{2}{*}{ Chemical composition } \\
\hline & Methanol & Ethanol & & \\
\hline $3575-3205$ & 3417 & 3381 & O-H Stretching vibration & Alkanes \\
\hline $3000-2840$ & $2950 / 2840$ & $2976 / 2895$ & C-H Stretching vibration & $\begin{array}{l}\text { Alcohols, ethers, carboxlic } \\
\text { acids, esters }\end{array}$ \\
\hline $1650-1640$ & 1649 & 1650 & $\mathrm{C}=\mathrm{C}$ Stretching vibration & Alkenes \\
\hline $1460-1400$ & $1450 / 1408$ & $1454 / 1421 / 1380$ & $\mathrm{CH}_{2}, \mathrm{CH}_{3}$ Flexural vibration & Alkanes \\
\hline $1090-1020$ & 1020 & $1090 / 1049$ & $\begin{array}{l}\mathrm{C}-\mathrm{O} \text { Stretching vibration and } \\
\mathrm{O}-\mathrm{H} \text { deformation vibration }\end{array}$ & $\begin{array}{l}\text { Alcohols, ethers, carboxlic } \\
\text { acids, este }\end{array}$ \\
\hline 881 & & 881 & $\begin{array}{l}\text { Anomeric carbon vibrational } \\
\text { frequency }\end{array}$ & Alkenes \\
\hline
\end{tabular}

Table 2: GC-MS analysis of kiwi fruit extracted by methanol

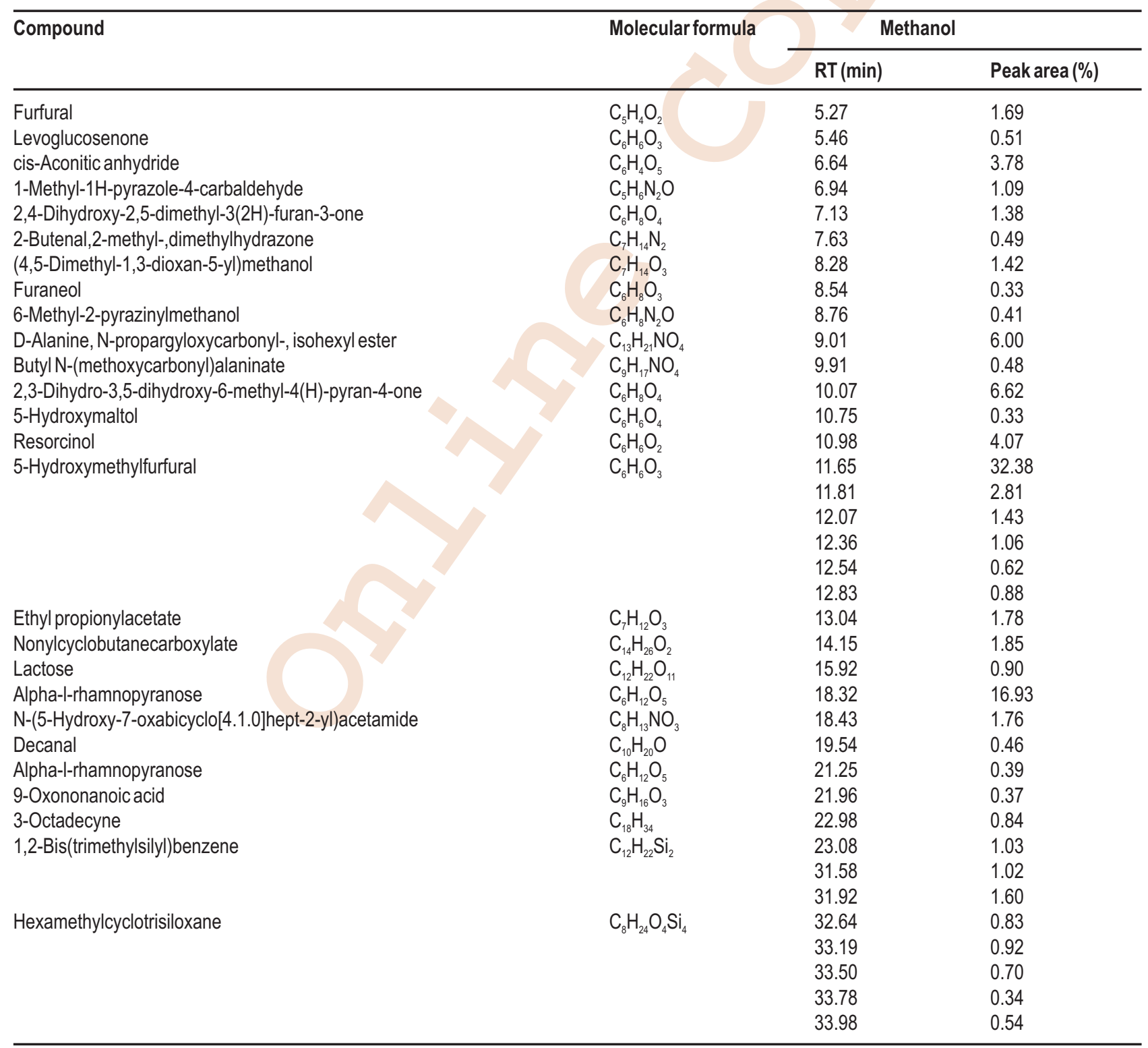




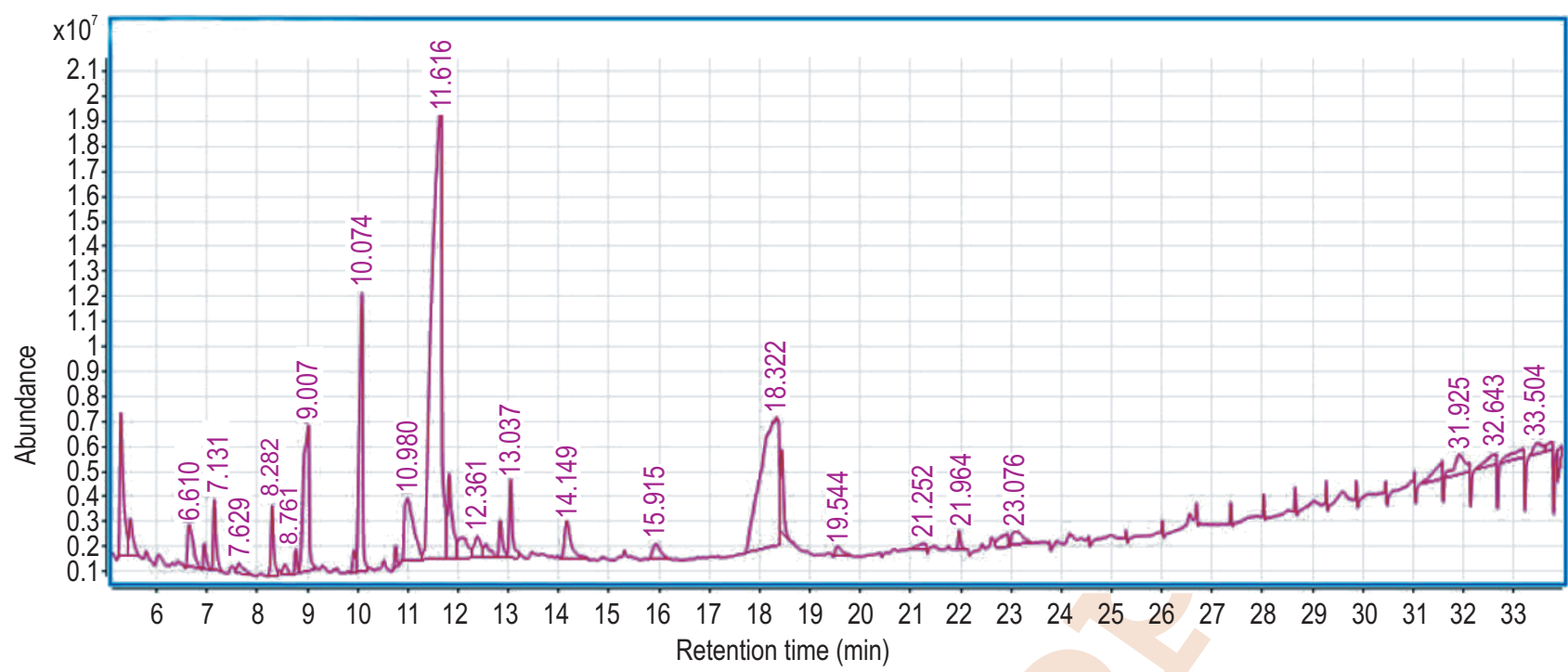

Fig. 2 : Total ion chromatograms of kiwi fruit extracted by methanol.

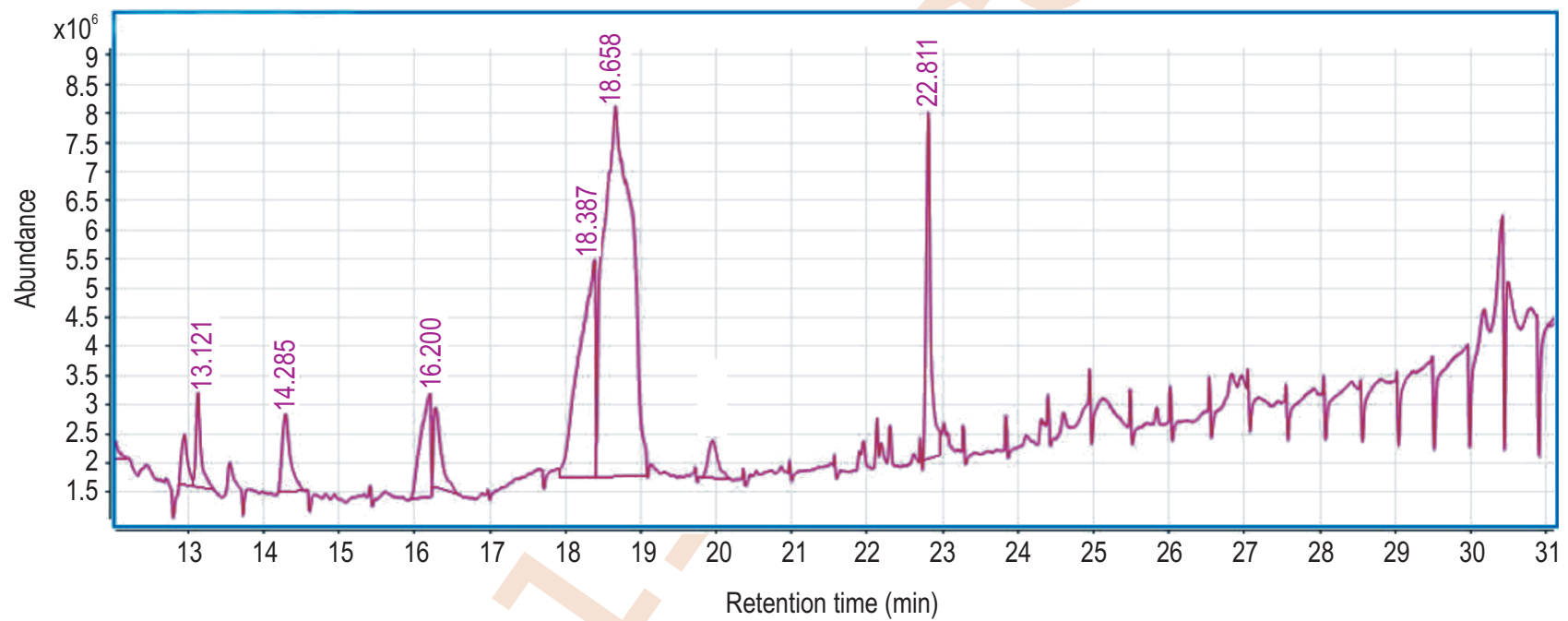

Fig. 3 : Total ion chromatograms of kiwi fruit extracted by ethanol.

sample. At $3000-2840 \mathrm{~cm}^{-1}$, the absorption peak was $\mathrm{C}-\mathrm{H}$ stretching vibration and at $1090-1020 \mathrm{~cm}^{-1}$, the absorption peak was $\mathrm{C}-\mathrm{O}$ stretching vibration and $\mathrm{O}-\mathrm{H}$ deformation vibration. These groups may be derived from alcohols, ethers, carboxlic acids and ester in the sample.

Ethanol was stronger than methanol for the transmittance of these wave numbers. This demonstrated that cellulose can be more effectively extracted by ethanol and can be detected at FTIR detection. At 1650-1640 $\mathrm{cm}^{-1}$, the absorption peak was $\mathrm{C}=\mathrm{C}$ stretching vibration. At $881 \mathrm{~cm}^{-1}$, the absorption peak was anomeric carbon vibrational frequency of ethanol. These groups may be derived from alkenes in the sample. The main chemical components of kiwi fruit were alkenes, alkanes, alcohols, ethers, carboxlic acids and ester.
Table 3 shows the GC-MS result of kiwi fruit ethanol leaching liquor. Thirty-six peaks were detected, and 19 chemical components were identified. The main components were 5hydroxymethylfurfural (33.50\%); dodecanoicacid, 3-hydroxy$(20.30 \%)$; melezitose $(12.22 \%)$; 3a, 6b, 8a-Trihydroxy-2a(hydroxymethyl)-1,1,5,7-tetramethyl-4-oxo-1a,1b,1c,2a,3,3a, 4, $6 \mathrm{a}, 6 \mathrm{~b}, 7,8,8 \mathrm{a}-d o d e c a h y d r o-1 \mathrm{H}$-cyclopropa [5',6'] benzo $\left[1^{\prime}, 22^{\prime}: 7,8\right]$ azuleno [5,6-b]oxiren-8-yl acetate $(7.11 \%)$; furfural (6.18\%); 4H-pyran-4-one,2,3-dihydro-3,5-dihydroxy-6-methyl(4.42\%); 7b-hydroxy-3-(hydroxymethyl)-1,1,6,8-tetramethyl1,1a,1b,4,4a,5,7a,7b,8,9-decahydro-9aH-cyclopropa[3,4]benzo [1,2-e] azulene-5, 9, 9a-triyl triacetate (3.3\%); 4-(1,5-dihydroxy2,6,6-trimethylcyclohex-2-enyl)but-3-en-2-one (3.17\%); 3methoxycarbonylpyrazole $(3.15 \%)$; cis-aconitic anhydride (1.16\%); resorcinol (0.95\%); 1,3-dioxane-4-methanol, 4,5- 
Table 3: GC-MS analysis of kiwi fruit extracted by ethanol

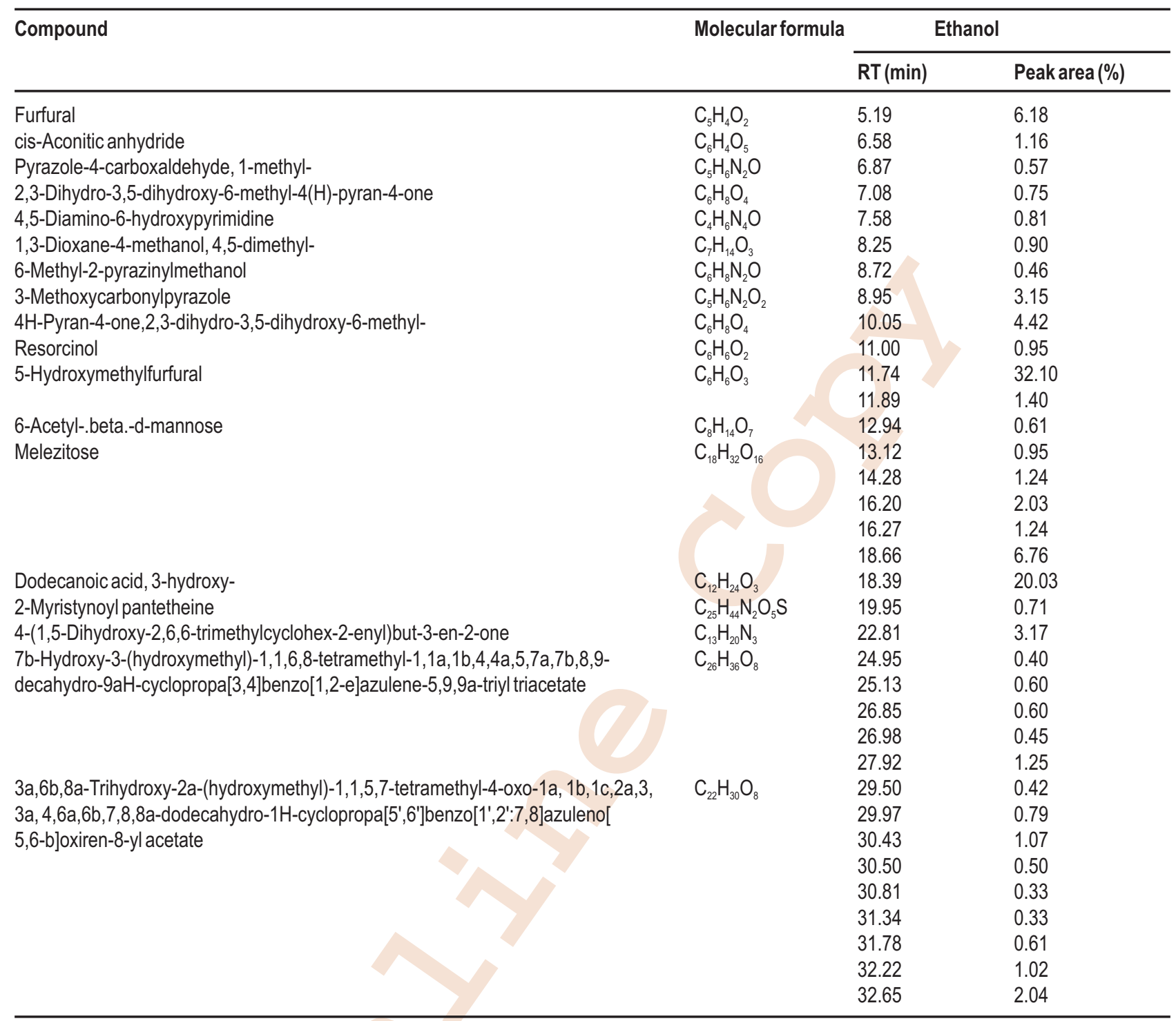

dimethyl- (0.9\%); 4,5-diamino-6-hydroxypyrimidine (0.81\%); 2,3dihydro-3,5-dihydroxy-6-methyl-4(H)-pyran-4-one (0.75\%); 2myristynoyl pantetheine $(0.71 \%) ; 6$-acetyl-beta.-d-mannose (0.61\%); pyrazole-4-carboxaldehyde, 1-methyl- $(0.57 \%)$; and 6methyl-2-pyrazinylmethanol $(0.46 \%)$.

In these two GC-MS detections, 34 chemical components were detected in total. Furfural, cis-aconitic anhydride, 6-methyl2-pyrazinylmethanol, resorcinol and 5-hydroxymethylfurfural were detected in both the extracts.

Chemical components function progress: 5Hydroxymethylfurfural is a kind of furan derivative. It has certain carcinogenic effect on rodents and has potential to be sustainable substitutes for petroleum-based building blocks used in the production of plastics and fine chemicals (Chheda et al., 2007;
Sachse et al., 2016; Shaikh et al., 2017).

Franeol has various biological activities on animal models. Having a broad spectrum of antimicrobial activity on human pathogenic microorganisms, it has antifungal effect and can act as a therapeutic agent (Sung et al., 2006; Sun et al., 2017; Nkambule and Mukeredzi, 2017; Sharafizad and Coetzer, 2017).

Levoglucosenone (1,6-anhydro-3,4-dideoxy-b-Dglycerohex-3-enopyranos-2-ulose) is used in the synthesis of tetrodotoxin, multistriatin, rare sugars, Ras activation inhibitors, and a variety of other natural products (Wang et al., 2011). It is used in the preparation of chiral inductors for asymmetric organic synthesis. Further, it is also used as chiral synthon in the synthesis of a multitude of natural and unnatural products (Sarotti etal., 2007). 
Decanal naturally occurs in kiwi, citrus, tomatoes, strawberries and other fruits. It is commonly used as perfume. It may also have the potential as an antioxidant, antimicrobial and antitumor, and is often used in food, cosmetic and pharmaceutical industries (Liu et al., 2012; Fu and Liu, 2017; Ge et al., 2017; Davis, 2017).

Ethylpropionylacetate is used as a suitable solvent for paints, printing ink, nitro spray paints, varnishes, various resins, and is also used in the essence and spice industries for mild fruity fragrance. Furfural is a raw material used for preparing many medicines and industrial products. It can be used as synthetic resins, varnishes, pesticides, pharmaceuticals, rubbers, coatings, etc.

Furfural is produced by dehydration and hydrolysis of xylan contained in ligocellulose. Its derivatives are potential biofuel components with a rich source, and it deserves attention as a potential bio-fuel (Lange et al., 2012; Cho, 2017).

\section{References}

Abd Samad, N.S., A. Amid, D.N. Jimat and N.A.A. Shukor: Isolation and identification of halophilic bacteria producing halotolerant protease. Sci. Herit. J., 1, 07-09 (2017).

Alfarooq, O.B., M.M. Marlia and M.J. Abdulhasan: A study on water quality from Langat River, Selangor. Acta Sci. Malays., 1, 01-04 (2017).

Atikuzzamman, M., M.A. Islam, M. Moniruzzaman and M.S. Islam: Vendors and consumers status and microbiological analysis of some common fast food items of different fast food restaurants in Barisal City. Malays. J. Halal Res., 1, 17-21 (2018).

Chheda, J.N., Y. Románleshkov, and J.A. Dumesic: Production of 5 hydroxymethylfurfural and furfural by dehydration of biomassderived mono- and poly-saccharides. Green Chem., 9, 342-350 (2007).

Cho, T.: Innovative micro-dust reduction technologies. Acta Chem. Malay., 1, 04-07 (2017).

Davis, S.: The distribution of prime pairs differing by 2. J. Discrete Mathem. Scie. Cryptogr., 20, 1053-1068 (2017)

De'nan, F., F.M. Nazri and N.S. Hashim: Finite element analysis on latera torsional buckling behavior oi i-beam with web opening. Eng. Herit. J., 1, 19-22 (2017).

Ge, S., Z. Liu, Y. Furuta and W. Peng: Characteristics of activated carbon remove sulfur particles against smog. Saudi J. Biol. Sci., 24, 13701374 (2017).

Halin, N.I.A., F. Huyop, T.H. Tengku Abdul Hamid, K.B. Abdul Halim and A.A. Abdul Hamid: In silico binding interactions of dehalogenase (Dehe) with various haloalkanoic acids. Eng. Herit. J., 1, 04-06 (2017).

Herrera-Franco, T., N. Gavín-Quinchuela, P. Alvarado-Macancela and Carrión-Mero: Participative analysis of socio-ecological dynamics and interactions. A case study of the Manglaralto coastal aquifer, Santa Elena-Ecuador. Malays. J. Sustain. Agric., 1, 19-22 (2017).

Howlader, M.H.K., M.N. Islam, S. Biswas, M.E. Uddin, A. Shila, M.Z. Haque and N. Mahmud: Salt tolerance of chili genotypes during germination and seedling growth. Malays. J. Halal Res., 1, 01-07 (2018).

Hua, L.I., T.U. Zheng and H. Wang:Analysis of aroma components of kiw fruit (Actinidia chinensis planchon) by gas chromatography-mass spectrometry. J. Instrum. Anal., 21, 58-60 (2002).

Lange, J.P., V. Jeroen, X. Buijtenen and R. Price: Furfural A promising platform for lignocellulosic biofuels. Chemsuschem, 5, 150-166 (2012).

Liu, J.J. and W.H. Chen: Determination of trace elements in fruit of Actinidiachinensis Planch. Biol. Trace Elem. Res., 8, 239-240 (2001).

Liu, K., Q. Chen and Y. Liu: Isolation and biological activities of decanal, linalool, valencene, and octanal from sweet orange oil. J. Food Sci., 77, 1156-61 (2012).

Ma, Q.Z., D.Q. Zhang and W.X. Peng: Determination of chemical Components of Benzene/Ethanol Eztractives of Chinese-fir wood by GC/MS[C]. In: $2^{\text {nd }}$ International Conference on Bioinformatics and Biomedical Engineering, pp. 3196-3198 (2008).

Nkambule, T. and T.G. Mukeredzi: Pre-service teachers' professional learning experiences during rural teaching practice in Acornhoek, Mpumalanga Province. S. Afr. J. Educ., 37, 1-9 (2017).

Nødtvedt, O.O., A.L. Hansen and B. Bjorvatn: The effects of kiwi fruit consumption in students with chronic insomnia symptoms: A randomized controlled trial. Sleep Biol. Rhythms, 15, 159-166 (2017).

Sachse, B., W. Meinl and Y. Sommer: Bioactivation of food genotoxic ants 5-hydroxymethylfurfural and furfural alcohol by sulfotransferases from human, mouse and rat: A comparative study. Arch. Toxicol., 90, 137-148 (2016).

Sarotti, A.M., R.A. Spanevello and A.G. Suárez: An efficient microwaveassisted green transformation of cellulose into levoglucosenone. Advantages of the use of an experimental design approach. Green Chem., 9, 1137-1140 (2007).

Shaikh, M.M., A.O. AlSuhaimi, M.M. Hanafiah, M.A. Ashraf, A. Fantoukh, and E. AlHarbi: Leachable volatile organic compounds from polyethylene plumbing plastic pipes: A case study of Medina Al Munawarah, Saudi Arabia. Acta Chem. Malay., 1, 01-03 (2017).

Sharafizad, J. and A. Coetzer: Women business owners' start-up motivations and network structure. J. Manag. Organiz., 23, 206$223(2017)$.

Sharma, D. and K.D. Yadav: Vermicomposting of flower waste: Optimization of maturity parameter by response surface methodology. Malays. J. Sustain. Agric., 1, 15-18 (2017).

Sun, H., V.I. Varankina and V.V. Sadovaya: Didactic aspects of the academic discipline "History and Methodology of Mathematics". Eurasia J. Math., Sci. Tech. Ed., 13, 2923-2940 (2017).

Sung, W.S., H.J. Jung, and I.S. Lee: Antimicrobial effect of furaneol against human pathogenic bacteria and fungi. Int. J. Microbiol. Biotechnol., 16, 349-354 (2006)

Wang, L.S. and W.X. Peng: Py-GC-MS analysis on biomass energy components from wood extractives of Eucalyptus urophydis under high temperature. Appl. Mech. Mat., 164, 30-32 (2012).

Wang, Z., Q. Lu and X.F. Zhu: Catalytic fast pyrolysis of cellulose to prepare levoglucosenone using sulfated zirconia. Chemsuschem, 4, 79-84 (2011).

Wang, Z.D.: Evaluation of ecological functions of green land system in Nanyang City. J. Anh. Agric. Sci., 36, 13138-13141 (2008).

Yong, T. and Q.X. Zhou: Environmental effect of Sudan I-IV: adsorption behaviors and potential risk on soil. Acta Sci. Malays., 1, 14-15 (2017).

Zahan, T., A. Hashem, M.M. Rahman, R.W. Bell and M. Begum: Efficacy of herbicides in non-puddled transplanted rice under conservation agriculture systems and their effect on establishment of the succeeding crops. Acta Sci. Malays., 2, 17-25 (2018). 